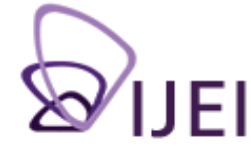

International Journal for Educational Integrity

\title{
An investigation into plagiarism motivations and prevention techniques: Can they be appropriately aligned?
}

\author{
Rebecca Awdry \\ University of Canberra \\ rebeccaawdry@yahoo.co.uk
}

\author{
Rick Sarre \\ School of Law, University of South Australia \\ rick.sarre@unisa.edu.au
}

Keywords: plagiarism, criminological theory, education policy, deterrence, Turnitin

\begin{abstract}
This paper focuses on the emergence and expansion of the phenomenon of plagiarism in higher education. Through a mixed-method investigation, and by applying appropriate criminological theory, it explores the student motivations that have been identified as leading to plagiarism, and tests the means employed by higher education providers to combat it. The article highlights an apparent disconnect between the perceived realities of both student and education provider. It concludes that this disconnect must be carefully considered so that higher education providers can develop effective policies to prevent academic misconduct rather than exacerbate it.
\end{abstract}

\section{Introduction}

There is a general consensus that plagiarism is rife today within higher education, where a key emphasis is placed upon students' self-study. This should come as no surprise to anyone, given the burgeoning number of international electronic forms of instruction. Indeed, it has been asserted that students now have the ability to produce entire dissertations without ever having to enter a library or open a book (Kelly, 2006). In his work, The cult of the amateur, Keen (2007) outlines the cultural changes that have developed from advances in technology, arguing that the number of reference websites, blogs and forums on the internet have created a plethora of truths connected to every subject. Carroll (2007), in her work on plagiarism, similarly explores the idea of implicit ownership. She protests that inherent individual ownership is impossible, due to the proliferation of ideas and analyses produced on every conceivable subject.

Regulation of reference sites, such as Wikipedia, is minimal, and a new internet culture has enabled a generation of intellectual kleptomaniacs who simply cut and paste with ease (Keen, 2007; Robin, 2004). As Berlins (2009) contends, cheating has always been found within education, but the internet and digital technologies have taken it to far higher levels than ever before, whether through enabling technologies or simply by virtue of our new-found tools of detection. Nowadays, for example, there are hundreds of websites available that allow students to download pre-written assignments. As Park (2003, p. 481) states: "The Internet provides unparalleled temptation and almost unrestricted opportunities for students to cheat...". When one combines the temptation to cheat, the simplicity with which copying and pasting from existing online work can be done, and the increased use of text-matching detection software in higher education, it is little wonder that an increasing number of institutions have documented an increase

The International Journal for Educational Integrity is available online at:

http://www.ojs.unisa.edu.au/journals/index.php//JEI/

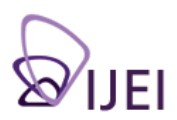


in the instances of plagiarism discovered. Consequently, they are searching for more effective methods and policies that can address the problem.

\section{Explanations for plagiarism}

There are many reasons cited in the literature as factors that contribute to plagiarism, including students' poor time management (Carroll, 2007), poor organisational skills, and lack of understanding of research methods in a given subject area. Bennett (2005), based upon his interviews with students, found the biggest causes of significant plagiarism in students' work were connected to, or derived from, parental pressure, fear of failure, and poor grades, and were more commonly found amongst English as an Additional Language (EAL) students who, indeed, regularly suffer from multiple factors (see also Sergiou, 2004). EAL students regularly cited cultural misunderstanding as contributing to their plagiarism, rather than deliberate plagiarism (Carroll, 2007; Park, 2003). EAL students have also been known to cite difficulties in language as a factor in their drift towards plagiarism. As they struggle to put the concepts and ideas they are researching into their own words, they find it easier to take the text from elsewhere (Carroll, 2007). These reasons have been identified as 'techniques of neutralisation' (Sykes \& Matza, 1957), expanded upon below.

Other explanations for student plagiarism, identified by Park (2003), include a genuine lack of understanding of the rules regarding citation, the desire to gain a higher grade, poor time management, personal values (i.e. no belief that plagiarism is wrong), defiance of authority, negative attitudes towards tutors, temptations and opportunities offered to students, and a lack of any deterrent threat by the relevant Higher Education Institution (HEI).

These explanations are, moreover, supported by a number of criminological theories, too, generally referred to as 'classical' theories. For example, the Rational Choice Perspective (RCP), also known as the Rational Choice Theory (RCT), as proposed principally by Clarke (1997), Clarke and Cornish (1986) and Clarke and Felson (1993), contends that offenders weigh up the benefits of their actions against the risks of potential sanctions before deciding on their course of conduct. Deviants, according to this view, rationally decide on the best outcome for themselves in any given situation. These authors posit that crime is a purposive act and that all people are predisposed to criminality if the right balance of factors is present. RCT is aligned with deterrence theory, which is based upon the notion that offenders weigh the gains to be made by offending against the pain to be borne if they were to be caught (Akers, 1990). On this view, the best response to plagiarism is to raise the deterrent threat, thereby making the pain of being caught so odious that it outweighs the pleasure of getting a better grade with minimal effort (Park, 2003; Sergiou, 2004).

Situational Crime Prevention (SCP) is the natural ally of RCT. SCP accommodates the changing nature of crime in the face of changes in technology. SCP is premised upon the understanding that a person is less likely to yield to the temptation that RCT says is always there, once the task becomes too difficult. It confirms that, if prescribed conditions are correct, humans will take advantage of a situation to benefit themselves (Akers, 1990). Tilley (2009) adds that, as crimes are changing, all new motivations, opportunities and methods need to be investigated and responded to (see also Hirschi, 2002; Ekblom \& Tilley, 2000).

One of the best examples of SCP is the concept known as Designing Out Crime. It builds on the objectives of RCT and SCP, but places an increased emphasis on risk management and crime analysis. For example, it assigns to individuals and companies a responsibility to design preventative technologies/strategies (Hughes \& Edwards, 2005). If HEls were to tackle plagiarism on the back of this concept, they would design measures that would make the facilitation of plagiarism more difficult, for 
example, detection software that raises the fear of detection (Carroll, 2007). Through the use of text-matching software, such as Turnitin, HEls are protecting the integrity of their degrees.

It has been argued by some authors (Ekblom, 2000, 2005; Kantor, 2006) that the technology that has made crime easier, along with the technology that has made it more detectable, has created a technological 'arms race'. Both 'combatants' are continuing in a battle to out-smart each other in the commission and detection of crime. This theory can equally be applied to plagiarism. Carroll argues that it is natural to see the solution to 'copy and paste' plagiarism as being technological, although it will “...lead to a never-ending 'arms race' between the students and the university" (Carroll, 2007, p. 72).

\section{The research study}

A study was conducted at a UK HEl in 2010/11 to establish the reasoning and explanations that students provided when caught engaging in plagiarism. The study was also designed to test the deterrence initiatives that had been employed to address it. The study looked at the frequency with which students stated that plagiarism occurred. Through a comparative analysis, it also sought to address a perceived disconnect in thinking between tutors and students concerning why plagiarism occurs and how to combat it. For example, in recent years there has been a huge increase in students buying tailor-made assignments from online companies. Essay writing sites are producing huge revenues and a suitably titled Guardian article sums up the market:

Q: How do you make $£ 1.56 \mathrm{~m}$ a year and drive a Ferrari? A: Sell essays for $£ 400$. (Taylor, 2006)

\section{Methodology}

A mixed method approach was employed to produce data that complemented and responded to the objectives of the study, enabling policy implications for the HEI to be inferred. The first study was a focus group study undertaken with staff. The second study was a self-reporting survey undertaken by students. Each is dealt with, in turn, below. The discussion that follows draws the ideas and conclusions from both studies when read together.

\section{Focus group (staff) study}

Six academics (tutors) involved in the HEl's Academic Misconduct panels, from different academic departments, were invited to discuss their experience and interpretations of the motivations leading to plagiarism, the subsequent penalties imposed on these students, and the control strategies used by their school in attempting to prevent plagiarism ${ }^{1}$. The responses were analysed using criminological theory to attempt to increase understanding of the reasons behind plagiarism and the most effective prevention policies. The key theories discussed were linked to Situational Crime Prevention (frequency discussed: 29 responses); Designing Out Crime (and the idea of an arms race) (29); techniques of neutralisation (29); Rational Choice Theory (28) and deterrence strategies generally (23).

\section{Findings from the focus group study}

According to tutors, one of the main reasons for plagiarism is related to mitigation. Students would most commonly cite external factors as the reasons behind their plagiarism. These reasons ranged from lack of time, the necessity to work increased hours in employment, family and personal commitments, having to help friends, and other extenuating circumstances. 
The above reasons may best be explained by reference to the concept of 'techniques of neutralisation' developed by Sykes and Matza (1957). The first technique of neutralisation, 'denial of responsibility', is when students maintain that they have been a victim of circumstance; they were put into the situation by factors outside of their control. Culture and language excuses were frequently utilised by EAL students, too, in respect to 'neutralising' their actions. These groups argued that they had not received the appropriate educational background to train them on the standards expected of $\mathrm{HEIs}$, or that language barriers forced their hand.

...if you've written something, how could I write what you've written any better? So you have that culture... (I\#6)

Some respondents sought to rationalise their actions by arguing that they had to carry out the plagiarism because of external pressures. This is an example of the 'appeal to higher loyalties' technique (Sykes \& Matza, 1957). Two clear examples which arose from the tutors' observations were that future employment prospects or parental expectations put pressure on some students to achieve high grades; these expectations then pushed them into having to steal work/text from other sources in order to succeed.

All tutors gave examples of instances where they felt that students would cheat if they thought that they would not be caught.

\#2 quoted a student as saying:

Yeah if I can get away with it, l'll do it, it's like it's an achievement to get away with it.

\#1 added that tutors showing a more stringent system for checking work would provide more of a risk for students wanting to plagiarise. He argued that plagiarism was "an active process, not a passive consumption". All tutors contended that students were rational thinking individuals who would consciously decide upon their actions and weigh up the risks. This was also apparent because mitigating factors presented by students were discussed in a negative context, as tutors did not feel that these were valid or true representations of what had led to the student completing the work dishonestly.

What became apparent in the discussion relating to RCT was that the tutors all believed that if there were harsher penalties, better detection processes for plagiarism and more awareness of the issue, the risks would increase so greatly that the prevalence of plagiarism would decrease. The possibility of submitting plagiarised work to obtain high grades would be a benefit outweighed by the strong possibility of being caught. This led to discussion regarding the value of deterrence in policymaking. Consider the following exchange between focus group participants:

\section{I\#1: Do you think the penalties are harsh enough?}

I\#5: I think the penalties are harsh enough; I don't think we apply them harshly enough. It's very difficult, isn't it? I know that l've made mistakes and l've done stuff wrong and I would hate to see someone, a young person's life, destroyed because of a foolish error that they've made, which is really in the scale of things, not really that critical but...

\section{I\#2: Hang on. Not really critical!?}

I\#5: I think there's things like a first offence and a learning experience but then when people have been given those opportunities and they've shown that they're not trying to correct that. ... But l'm really uncomfortable with some of my 
colleagues who are very much "any cheating and they should be out straightaway". I'm really uncomfortable with that because I think, as I say ...

I\#2: You are here to learn ...

1\#5: Everybody in this room has made mistakes and some of those mistakes have been more serious than others. I think everybody deserves some amount of leniency initially to sort things out and put things right.

I\#6: I think that's a fair point ...

It was surmised by the tutors that deterrence was a valid means of combating plagiarism. Consistency, transparency and definitive systems and processes were also presented as essential in creating an effective deterrent for students so that there were no opportunities for a gap to be created where plagiarism would go either undetected or un-penalised.

One of the biggest proactive factors presented related to tutors believing that students would not necessarily plagiarise if assignments were tailor-made and less generic, giving less opportunity for the work to be copied from other sources. Further, setting students 'seen' exams would allow them the opportunity to research on the internet, but not copy and paste. It may indeed be possible to 'design out' crime, and as I\#4 put it:

...some staff claim that they are designing pieces of work that are plagiarism proof!

A tailor-made topic would be the natural choice of a tutor/instructor who was an advocate of design strategies as a means of crime prevention. On this view, plagiarism can be avoided by tutors adapting teaching methods and information given to students such that they are less likely to find accessing online material useful.

Proactivity was also promoted through the use of Turnitin. This was used by tutors not only as a means of determining text matches in students' work, notifying them to possible plagiarism, but also as a way of alerting students to the possibility that their work had been copied by others.

It was further postulated that showing students what the software was capable of would have a deterrent effect. Moreover, the software would aid the teaching process by showing where citations had not been properly attributed, giving students a clearer understanding of referencing expectations.

Turnitin provides educational establishments with the power to scan work and determine if areas of students' work is not original, and whether text matches have been appropriately cited. However, as suggested by the focus group, text-matching software has seemingly led to a never-ending arms race with the students. This theme ran throughout the focus group, and the terminology itself was used directly by respondents at five separate discussion points ${ }^{2}$.

It's an 'arms race', it's almost like it's a competition then to see if they can get it past the system. (I\#2)

Copying and pasting has developed from taking information from books, to copying from the internet. This point led to some remarks in the focus group that students have altered specific wording throughout the text to attempt to hide their plagiarism. The group was of the unanimous view that, given the power of text-matching software, 
students now regularly resorted to wholesale copying and purchasing bespoke work from other students and online sources, which could not be detected by Turnitin. This developed further in discussion:

...the use of Turnitin has helped to reduce the large number of cases of copying. However, it's encouraged the business in writing assignments. (I\#4)

All focus group participants felt that tutors were in constant competition with students who use technologies to try to work around the software in order to cheat. The idea of a technological arms race with the students was, however, viewed in a very negative light. Tutors $\$ 2$ and $\$ \# 5$ argued that it had reduced the process of marking and grading into a mechanistic process, with too strong a focus on percentages of matching text in assignments, over focuses on referencing and substance. Some courses allowed students to submit their work to the software and to alter areas which were shown to have not been correctly referenced. However, those allowing them to submit their work numerous times to Turnitin prior to the submission deadline may have left themselves open to students exploiting the technology, giving them further opportunity to avoid detection through continued changes of copied text until it no longer matched. In responding to the discussion of submitting all work to Turnitin, I\#5 commented that he felt that the arms race had created a culture of mistrust within the institution and that there was a tendency to label students negatively, whereas only a minority were actually committing plagiarism. All respondents argued that the generalisation needed to be avoided when trying to create a culture of honesty amongst students generally, and specifically for the avoidance of plagiarism.

I\#2 summed it up well:

Trust. That is the thing that is going to prevent the plagiarism.

Instructors promoted their desire to have the penalties for plagiarism increased, opining that harsher penalties were required both as a form of retribution, for breaking university regulations, but also as an increased form of deterrence. One of the tutors stated that he felt penalties should be scaled according to the extent of plagiarism and whether it was a first or second offence.

\section{Self-reporting survey (students) study}

An anonymous survey was placed online through a survey website, and advertised around the campus of the HEl through flyers and information at central student administration points. Respondents were asked for their age, gender, and degree programme to assess prevalence among specific demographics ${ }^{3}$. They were further asked for their opinions on people cheating, what the penalties should be, their awareness of the Turnitin software, and whether they had ever plagiarised, with their reasons for or against doing it. The questionnaire was completed by 98 females and 84 males (1 gave no gender), giving a percentage split of $54 \%$ female to $46 \%$ male. The gender divide is similar to the demographics of students found at the HEI $(49.6 \%$ female, $50.4 \%$ male). Age boundaries were also evenly spaced. Anonymity was guaranteed.

Only convenience sampling and snowballing amongst students occurred. The student data gathered, then, was not evenly dispersed throughout the student body nor was it proportional to the demographics seen on different degree programmes. The sampling frame was narrow for both sets of respondents, and therefore findings presented cannot be generalised to the wider higher education community.

Findings from the self-report study

The study revealed that male respondents were more likely to plagiarise than the female respondents. Responses given by female students indicated that their 
plagiarism was often unintentional, which could imply a lack of understanding of academic writing skills, rather than male respondents who deliberately plagiarised their work $(7 \%$, versus $1 \%$ of females). In contrast, there were an equal number of students, of both genders $(13 \%)$, who were suspected of plagiarism by the HEl.

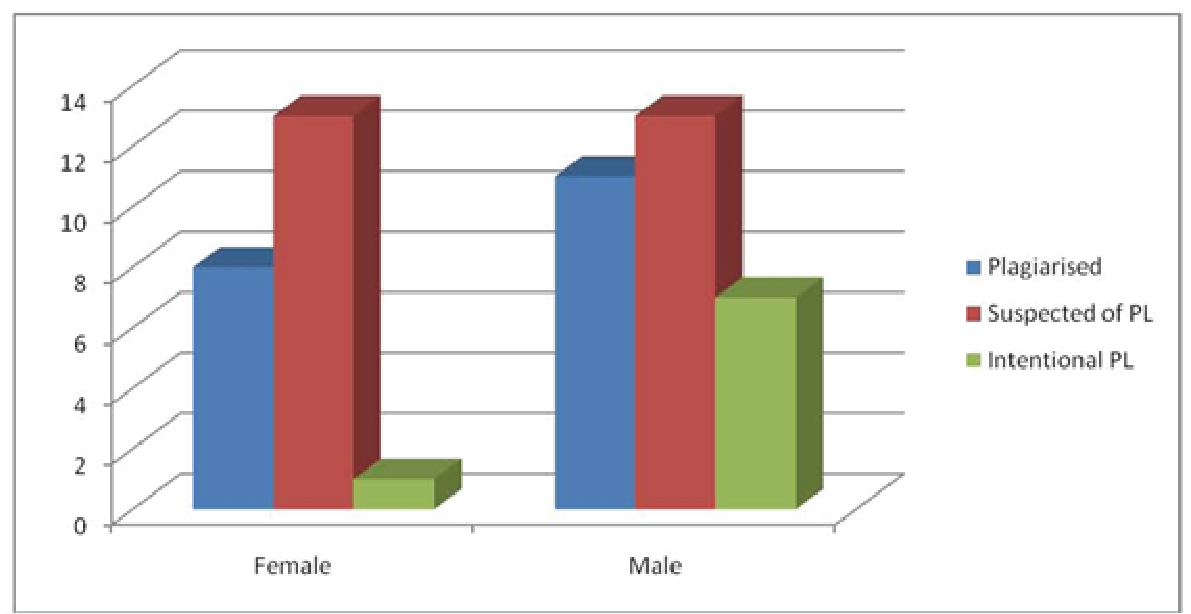

Figure 1: Gender by percentage of respondents who reported that they had plagiarised

It was found that two age groupings were more likely to both carry out plagiarism and be suspected of it by the HEI: 18-21 and 22-25 year olds. Data indicated in the sample that, as students get older, they are less likely to plagiarise. There were no reported instances of plagiarism for anyone in the 41+ age group (though a limited sample of only 15 responses).

Figure 2 shows the instances of plagiarism (suspicion and intentional) reported by the sample (albeit small) of the five academic departments (this did not correlate with actual instances of plagiarism investigated in each department of the case study HEI).

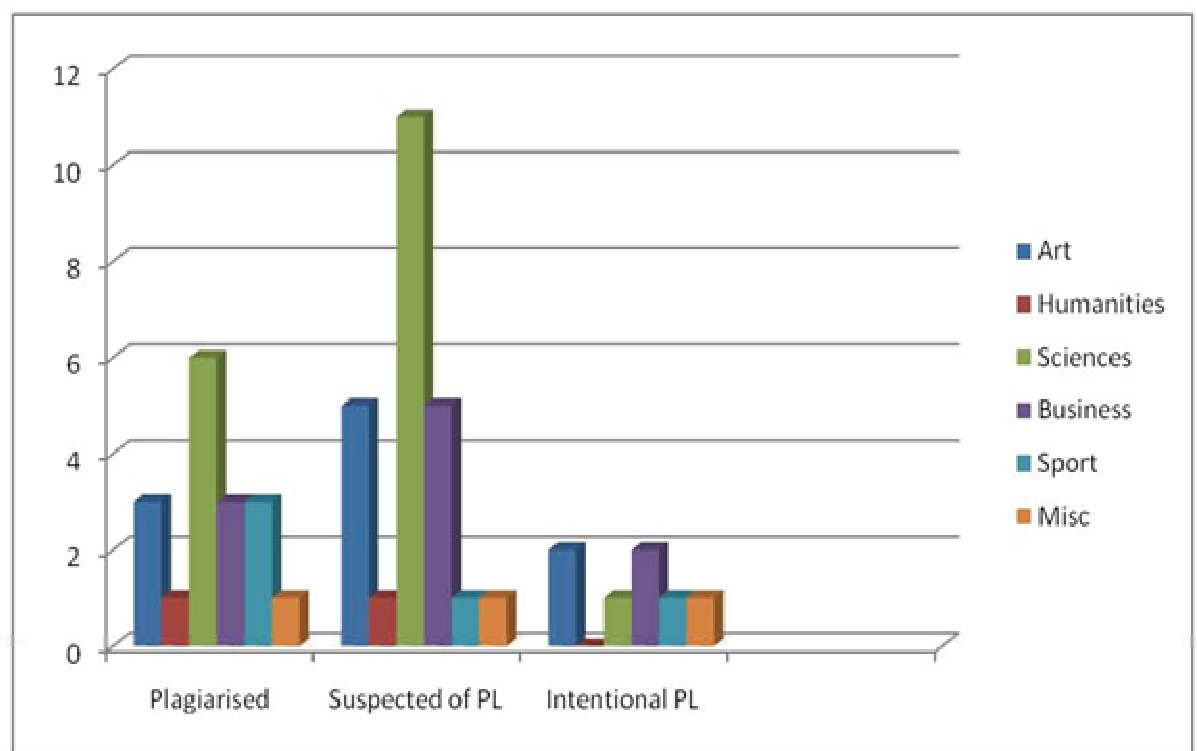

Figure 2: Department by number of respondents who had plagiarised 
The data indicated that whilst many instances of plagiarism are detected, there are high numbers of students whose plagiarism is undetected ( $35 \%$ of the sample, 64 respondents).

Respondents were asked to explain their plagiarism. The factors given were: ran out of time; desire to gain a higher grade; did not know how to do the work; and temptation from external sources. One respondent added that he or she would plagiarise again as it had enhanced their work. Other responses indicated that some students are looking for an 'easy way out' and would choose to plagiarise rather than complete the work themselves. Students were further asked to state whether they would plagiarise if they knew that they wouldn't be caught; $17 \%$ responded that they would plagiarise.

Respondents were asked to mark all factors from a list, presenting reasons why they would not plagiarise. They could choose to mark as many factors as they wished. The responses are laid out in Figure 3 below:

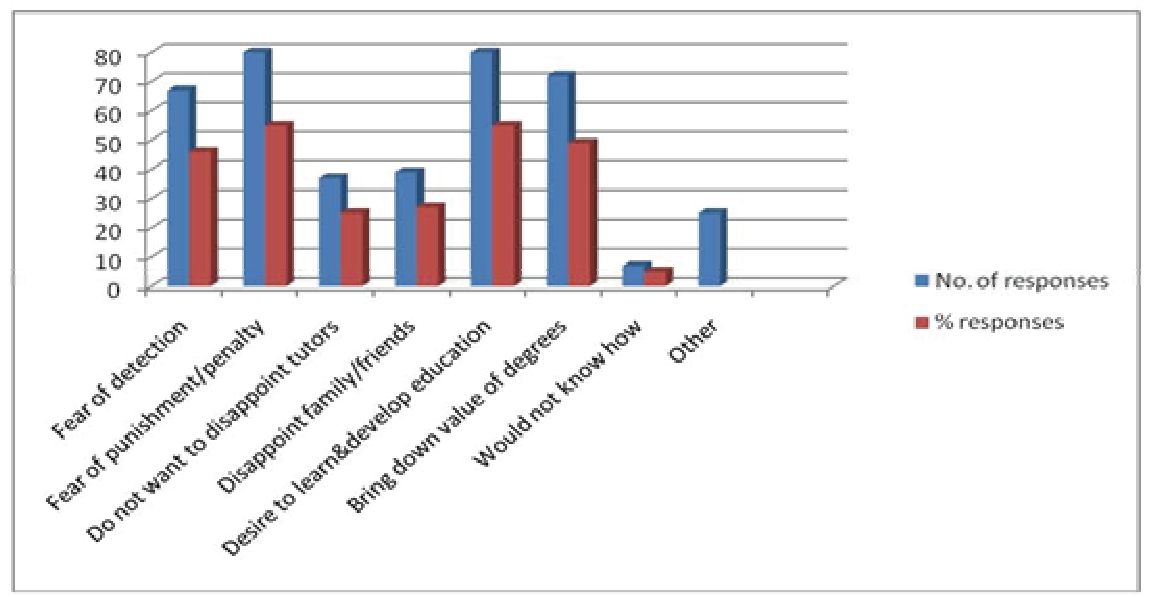

Figure 3: Reasons why respondents would not plagiarise

The highest two factors contributing to students not plagiarising was that they wanted to develop and learn from their education, and that they feared the penalties for doing it (55\% of respondents, $n=92)$. This demonstrates that, alongside theories of deterrence, students also considered their own personal development to be important, rather than focusing simply on the easiest way to complete their work. Forty-six per cent of students stated that they would not plagiarise due to the risk of being caught. The third largest factor chosen as a reason to not plagiarise was the desire to maintain the value of their degrees.

Respondents were also given the opportunity, in an open-ended question, to add anything further about factors that stopped them from plagiarising. The responses were categorised into two main areas. The most common responses related to the ethical and moral dimensions, that it is cheating and dishonest. The second factor was the desire to learn, connecting it to the value of degrees and the need to prove that they can do the work. The following quote epitomises several comments made by the students:

I want credit for MY own work, and to achieve without using unfair means. Cheating would only serve to cheat myself of the chance I have been given to succeed. (Respondent) 
It should be noted that no comments related to fear of detection or punishment, or concern in disappointing anyone else. All comments specifically focused on the educational importance of academic skills, development of knowledge and the dishonest nature of plagiarising, which also places unfair advantage on those not completing their work in the manner that most students do.

The majority of student responses relayed the idea that those who commit plagiarism do so through a lack of self-control, or a poor connection with the ideals of education, disconnecting themselves from the learning processes promoted by the HEI (responses 3, 4, 7, 9, 11-15, 19-24, Appendix 1). Some respondents even used the term 'immoral' to describe reported plagiarism. Students were asked to state whether they knew about the software used to detect plagiarism; $74 \%$ were aware of Turnitin and understood what it was.

Students were asked to give further information on what they felt punishments for plagiarism should be. Respondents separated accidental plagiarism, minor 'copy and pasting' plagiarism, and wholesale copying (whether from other students, or purchased wholesale). Appendix 2 demonstrates the strong feeling that respondents want plagiarists to be dealt with sternly. Many students commented that this was because plagiarism discredits the honest work others had done. Students appear to want more severe penalties for those deliberately taking from websites or other people. This 'scaling' is informed by the view that penalties should reflect the severity of the offence (this was supported by respondents \#4, 7-10, 12, 17, 20 and 22 in Appendix 2). However, many argued against using detection software such as Turnitin, as it displayed a lack of trust on the part of the HEI, and that it would also highlight inadvertent plagiarism for people who did not have a full awareness of referencing skills.

\section{Discussion}

The study revealed that there is a marked disjunction between the opinions presented by students and the opinions held by the tutors in the HEl from which the data for the study was drawn. Inaccurate assumptions may be made, therefore, when policymakers frame plagiarism prevention policies, thereby providing an incorrect and disparate foundation to a non-diminishing problem. This reiterates the work of Bertram Gallant and Drinan (2006) who presented the importance of looking at academic integrity at an organisational level. They stated that the problem needs to be recognised as an institutional one, and the methods addressing it need to focus on collaborations between academics, administrators, management and students.

It is important to note that both sets of responses (from tutors and students alike) can be aligned with criminological theories. Tutors were seen to focus on classical theories connected to deterrence and punishment (the idea that students make a rational choice to plagiarise) and thus supported the notion that the threat of heavy penalties and clever software were integral to the fight against plagiarism ${ }^{4}$. Students' responses, in contrast, showed that they were more concerned with the moral dimensions of plagiarism than simply the means used to detect and punish it. An overwhelming proportion of the sample of students reported that plagiarism was cheating, and morally wrong. This implies that tutors may need to promote inclusion and social values within education, and instil moral sensibilities within the student body (demonstrating that it is not only dishonourable to complete work through cheating, but that their marks do not reflect reality and may cause them to achieve higher overall degrees than honourable, hard-working students).

In addition, tutors should focus less on the detection and punishment of plagiarism and more on the value of students completing their own work and valuing their own integrity. This finding is in line with the work of McCabe, Trevino and Butterfield (2001) 
who found that students themselves want to address the problem of cheating, and want to encourage honesty by introducing such ideas as the 'Honour Code', placing more emphasis on students themselves maintaining a culture of integrity within academia. Just as children are taught from primary school that cheating is wrong, so it should be that university students should be reminded of the importance of honesty and integrity.

However, there is no room for complacency. A small, yet significant proportion (17\%) of students also stated that they would cheat if they knew they would not be caught, highlighting the need to retain detection and the threat of penalty as specific deterrents. This does, however, demonstrate that the vast majority of respondents still placed importance on their integrity.

In conclusion, the findings highlight the need for HEls to align prevention policies with students' opinions of the ways that they believe plagiarism should be prevented and consequently punished. On this view, an $\mathrm{HEl}$ concerned with minimising the problem of plagiarism should place less emphasis on control (detection and punishment) and place more of a focus on the moral aspect of cheating. If the HEI continues to focus simply on the text-matching software available, and the penalties imposed, the disconnect between students and HEls will work against plagiarism reduction policies.

\section{Limitations of the study}

There are some limitations in these studies. A filter error in the survey eliminated one critical area of the questionnaire (relating to frequency of assessments bought), and this would need to be addressed for future studies. Although a positive number of responses was returned (183), these were not evenly dispersed throughout the HEI. If a more representative study were to be conducted, it would be necessary to disperse the survey throughout all programmes of study and subject areas to produce a more reliable analysis of the problem as an institution-wide problem. For a widespread investigation into this problem it would be useful to interview a larger proportion of staff from differing backgrounds in academia, especially those who did not confront plagiarism regularly. Moreover, a large proportion of the data given by staff also reflected the wider opinion of colleagues and second-hand observations, rather than presenting a primary source of data, limiting the strength of the focus group data.

\section{Future research}

This study has revealed issues that should be the subject of future studies.

1. Even though the findings of the case study are not generalisable, its methods allow for replication in other HEls, helping institutions to frame policy based on a collaborative response and opinion of plagiarism.

2. It could further be utilised in comparative studies investigating plagiarism across various settings. A more elaborate sampling frame would be required to broaden the research base. Also, a cross-sectional study within one HEI would help to establish whether trends of plagiarism can be found within particular courses.

3. Due to the ubiquity of the text-matching tool, Turnitin, students are aware that it is highly likely that any plagiarism conducted through copy and paste methods will be discovered, with a possible progression to avoid detection by purchasing work. This is so far undetectable, and an area where there are considerable loopholes in discovery and prevention techniques. Through conducting an anonymous survey with students focusing solely on bespoke 
assessment buying, researchers would be able to gain a clearer insight into the frequency of this type of plagiarism. The survey could be further developed in a comparative study to establish whether purchasing is focused in one gender, age group, subject area or any other demographic.

\section{Conclusion}

Plagiarism is an on-going problem in higher education today and HEls are constantly working against the technological tide that is making it more likely and less detectable. There are currently no software programmes that are able to prove the origins of a piece of work unless it has been copied and pasted from the internet or other students. Given these limitations, HEls are well advised to shift their focus away from detection and mistrust policies and towards policies that focus more upon student motivation and rationalisation.

Ultimately, the successes of plagiarism prevention policies will come from a combination of theories, addressing motivations, penalties, deterrence, and assessment design. A singular theory such as the rational choice perspective adds value to the discussion, but it cannot provide a panacea against plagiarism. Clearer analysis of student motivations will allow for a more effective formulation of prevention techniques. Listening to the student voice, staff training and student inclusion in the policy process will lead to a more effective prevention process that places more emphasis on the institutional system. Policymakers are challenged to broaden their outlook of preferred plagiarism prevention measures and look towards those strategies that take into account the reasons students give for their plagiarism in the first place, and to build on the value that most students place upon their personal integrity. A 'one-size fits all' plagiarism prevention policy that is solely deterrencebased is doomed to failure.

\section{End notes}

${ }^{1}$ Due to the responses relating to their experiences, several discussions also arose from observations of colleagues and did not rely solely on first-hand experiences. Therefore, some of the information presented below shows information not necessarily linked directly to respondents themselves. It should also be noted that such a focus group interview is a strong method of gathering in-depth qualitative data (Noaks \& Wincup, 2004), although due to their involvement in misconduct panels and the students accused of plagiarism, they may have an overly subjective view.

${ }^{2}$ However, some of the discussions emerged from conversations and hearsay amongst both the student and staff body, and therefore should be considered only as anecdotal.

${ }^{3}$ Due to the limited size of the study further demographics were not explored.

${ }^{4}$ Interestingly, the students commenting upon this called for more draconian penalties than the tutors.

\section{References}

Akers, R. (1990). Rational choice, deterrence and social learning. The Journal of Criminal Law and Criminology, 81(3), 653-676

Bennett, R. (2005). Factors associated with student plagiarism in a post-1992 University. Assessment \& Evaluation in Higher Education, 30(2), 137-162.

Berlins, M. (2009). Cheating has always been around in schools and universities - but the Internet is making it far worse. Retrieved January 2, 2010, from www.guardian.co.uk.

Carroll, J. (2007). A handbook for deterring plagiarism in higher education (2nd ed.). Oxford: Oxford Centre for Staff and Learning Development. 
Clarke, R. (1997). Situational crime prevention (2nd ed.). New York: Harrow and Heston.

Clarke, R., \& Cornish, D. (1986). Rational choice. In R. Paternoster \& R. Bachman (Eds.), Explaining criminals and crime. Los Angeles: Roxbury Publishing Company.

Clarke, R., \& Felson, M. (Eds.). (1993). Routine activity and rational choice, Volume 5. London: Transaction Publishers.

Ekblom, P. (2000). Future crime prevention. London: Home Office Publications.

Ekblom, P. (2005). Designing products against crime. In N. Tilley (Ed.), Handbook of crime prevention and community safety. Devon: Willan Publishing.

Ekblom, P., \& Tilley, N. (2000). Going equipped. British Journal of Criminology, 40(1), 376-398.

Gallant, T., \& Drinan, P. (2006). Organizational theory and student cheating: Explanation, responses, and strategies. The Journal of Higher Education, 77 (5), 839-860.

Hirschi, T. (2002). Causes of delinquency. New Jersey: Transaction Publishers.

Hughes, G., \& Edwards, A. (2005). Crime prevention in context. In N. Tilley (Ed.), Handbook of crime prevention and community safety. Devon: Willan Publishing.

Kantor, A. (2006). Technological arms race over plagiarism is worth watching. Retrieved February 17, 2010, from www.usatoday.com.

Keen, A. (2007). The cult of the amateur. London: Nicholas Brealey Publishing.

Kelly, K. (2006). Scan this book! Retrieved January 2, 2010, from www.nytimes.com.

McCabe, D. L, Trevino, L. K., \& Butterfield, K. D. (2001). Cheating in academic institutions: A decade of research. Ethics and Behavior, 11(3), 219-232.

Noaks, L., \& Wincup, E. (2004). Criminological research. London: Sage.

Park, C. (2003). In other people's words. Plagiarism by university students: Literature and lessons. Assessment and Evaluation in Higher Education, 28(5), 471-488.

Robin, R. (2004). Scandals and scoundrel. London: University of California Press.

Sergiou, K. (2004). Why do students plagiarise? London: London Metropolitan University.

Sykes, G., \& Matza, D. (1957). Techniques of neutralisation: A theory of delinquency. American Sociological Review, 22(6), 664-670.

Taylor, M. (2006). Q: How do you make $£ 1.6 m$ a year and drive a Ferrari? A: Sell essays for £400. Retrieved January 2, 2010, from www.guardian.co.uk/ uk/2006/jul/29/.

Tilley, N. (2009). Crime prevention. Devon: Willan Publishing. www.jiscaps.ac.uk 
Appendix 1

Responses given to the question: What are/would be your reasons for not plagiarising?

1. i can not see the reason for plagiarism.

2. Non since $\mathrm{i}$ dont indulge in it

3. It is simply something that you do not do!

4. It is cheating. More to the point, it is dishonest.

5. Don't need to

6. Have been 'caught plagiarising before in high school (too sophisticated language for student's age"), but was a mistake on teacher's part who didn't realise it was my writing style, determined to prove it is all my own work every time

7. Morals

8. it is possible to do it by accident, withiut realising.

9. moral and ethical concerns

10. pointlessness

11. Religious

12. It would never cross my mind. Wouldn't it be more difficult to try and change or hide someone elses words than just coming up with your own in the first place. Amyway, referencing is a good thing. It shows that you have been reading and taking in other opions so just say you've used someone elses views and opions in your work.

13. I want cresdit for MY own work, and to acheive with out using unfair means. Cheating would only serve to cheat myself of the chance I have ben given to succeed

14. Desire to learn to reference correctly and appropriately

15. Its an academic skill, its usefull

16. Why not just reference stuff that's not yours?

17. I prefer the sound of my own voice.

Me dont like other people English

18. To maintain the highest standard of good academic practice.

19. it's cheating!

20. don't see the point of cheating

21. I'd rather get a $C$ but know that is the $C 1$ deserve than get an $A$ and not get anything out of the learning process

22. It's unfair to pass off someone else's workfideas as your own!

23. I wouldn't want to disappoint myself and lie to myself about how able I am.

24. I would always want people to acknowledge my work, so for moral reasons as well

25. I think you get more marks for well referenced work than if you have only few references so what would be the point in not saying that youve read everything you had? 


\section{Appendix 2}

Responses given to the question: Do you believe that there should be differential punishments in relation to how plagiarism is dealt with, i.e. whether it is scaled according to the amount of text taken, and the credit value of the work?

1. Disqualified possible re take opportunities

2. Reject that piece of work

3. Ofcourse since it is a terrible practise. I personally call it 'deception'.

4. if an accident (ie hasnt happened repeatedly), or wrong type of reference no mark for piece of work, with resubmition only gaining a max of $40 \%$. if serious university may determine to withdraw student from course

5. Even if proven without a doubt they should still be given a second chance as everyone makes mistakes.

6. Work should simply not be accepted

7. Because you read so much as research, you might accidentally use a phrase that has stuck in your mind especially as you might be writing in a similar fashion, using the same kind of words they had, this would be plagism without realising it, and I do not thik you should be punished for it. But if you find an out of date book and use whole paragraphs, there is no way of tracing this and students can get away with it without punishment. So one is deliberate and one is accidental and if nobody knows how can there be a punishment?

8. Sometimes people slip up with one or two small items in an assignment. Others will happily rip off entire assignments.

Those who adhere to the latter should be sent down as they clearly have no intention of improving their own learning.

The occasional slip should have the assignment resubmitted and the minimum grade awarded along with a warning that a repeat offence could result in failing the year.

9. I agree that the piece of work should be re-done with a minimum achievable grade. I also think that a second plagiarism from the same person should mean they fail that piece of work with no alternative.

10. Depending on the amount of work plagiarised and the intention : resubmitting work omitting the plagiarism with penalty for lateness.

11. not sure

12. if it is only a small amount the marker should just ignore that part and mark the rest of the work. if it is a large amount i.e over $50 \%$ the paper should be given zero. and the pupil should have to resit.

13. You have a right to reply so if you've done it by mistake the board will know that. $A$ lie, is a lie, is a lie. As soon as you start scaling the punishment I think it will give students the impression that they have the possibility of "getting off lightly". Where I think the message needs to be clear cut and scaling would make it very wishey washey.

14. One standard penalty

15. Failure of piece of work

16. no, regularity could be considered.

17. Obvious plagiarism should be punished the same, acciental plagarism due to mistakes can be just a warning

18. getting thrown off your course.

19. yes, dismissed off the course

20. No, because at the early stages of undergraduate study there are genuine misunderstandings which can often be clarified with tutorials and possible rewrites e.g. the role of common knowledge is confusing for a lot of new students. But at dissertation level there should be zero tolerance - this should also cover collusive practice i.e. commissioned plagiarism from the now innumerable essay cheat sites etc.

21. if its wrong, and people know its wrong, they should be adult and accountable for their actions, so one standard penalty is correct

22. If someone has plagerised most/all of their work it should be an automatic fail with no resit and anything else would be an automatic fail with a resit. In both circumstances all work would be monitored from then on. 


\section{About the authors}

Rebecca Awdry is the Director of Academic Policy and Review at the University of Canberra. She has recently moved from Oman, where she worked as a consultant for a new academic institution, in creating the Academic Registry. She has previously worked in London and Cardiff (UK) where she produced university regulations and policies, and was for five years in Cardiff, the lead in producing systems which attempted to minimise academic misconduct, working closely with academic and administrative staff, and speaking to student representatives.

Rick Sarre is Professor of Law and Criminal Justice in the School of Law, University of South Australia, where he teaches criminology, policing studies, commercial law and media law. For the last three years he has been the Chair of the Academic Board of the University, and a member of University Council. He received an Australian Learning and Teaching Council citation as a nationally recognised tertiary teacher in 2008. He currently serves as the President of the Australian and New Zealand Society of Criminology (ANZSOC). 